\title{
Consumo Médio e Digestibilidade Aparente dos Nutrientes do Feno de Aveia (Avena sativa L.) e Ervilha (Pisum sativum L.) em Ovinos Submetidos a Dois Regimes Alimentares
}

\author{
Ivone Yurika Mizubuti ${ }^{1}$, Carlos Armênio Khatounian², Edson Luis de Azambuja Ribeiro', Marco \\ Antonio da Rocha ${ }^{1}$, Leandro das Dores F. da Silva1, José Moura Filho', Andrea Pereira Pinto ${ }^{3}$, \\ Walberto Costa Fernandes ${ }^{4}$
}

\begin{abstract}
RESUMO - O experimento foi realizado com os objetivos de determinar o consumo médio diário (CMD), o coeficiente de digestibilidade aparente (CDA) dos nutrientes do feno de aveia e ervilha e avaliar o balanço de nitrogênio em ovinos. Foram utilizados dez ovinos machos, castrados, com peso médio de 36,64 kg, alojados em gaiolas para metabolismo, em um delineamento experimental inteiramente casualizado com dois tratamentos $(\mathrm{T} 1=80 \%$ de feno de aveia $+20 \%$ de ervilha e $\mathrm{T} 2=60 \%$ de feno de aveia $+40 \%$ de ervilha $)$ e cinco repetições por tratamento. Os tratamentos foram avaliados sob dois regimes alimentares (consumo voluntário e restrito). O CMD de matéria seca (MS) e fibra em detergente neutro (FDN) não diferiram entre tratamentos, e o CMD de fibra em detergente ácido (FDA) e fibra bruta (FB), foram maiores para o tratamento 1. Para animais sob regime de consumo voluntário, as médias de consumo desses nutrientes foram maiores para aqueles recebendo ração com $60 \%$ de feno $+40 \%$ de ervilha. Não houve diferença significativa entre os regimes alimentares para o coeficiente de digestibilidade aparente (CDA) da matéria seca (MS), extrato não nitrogenado (ENN) e proteína bruta (PB), entretanto, o CDA da matéria orgânica (MO), fibra em detergente ácido (FDA), fibra em detergente neutro (FDN) e fibra bruta (FB) foram maiores no consumo restrito. Observou-se que houve maiores CDA da MS, ENN, MO e PB no tratamento 2 e não houve diferenças entre os tratamentos para o CDA da FDN e FB.
\end{abstract}

Palavras-chave: consumo restrito, consumo voluntário, ruminantes

\section{Oat Hay (Avena sativa L.) and Pea (Pisum sativum L.) Nutrients Digestibility and Nutrients Average Intake by Sheep under Two Feeding Systems}

\begin{abstract}
This experiment was carried out with the objectives of determining the daily average intake (DAI), apparent digestibility coefficient (ADC) of oat hay and pea nutrients and to evaluate the nitrogen balance in sheep. Ten wethers with average weight of $36.64 \mathrm{~kg}$, alloted to suitable cages, were used. A completely randomized design with two treatments $(\mathrm{T} 1=80 \%$ oat hay $+20 \%$ pea and $\mathrm{T} 2=60 \%$ oat hay $+40 \%$ pea) and five replicates, was used. The treatments were evaluated under two feeding systems (voluntary and restrict). Daily average intake of dry matter (DM) and neutral detergent fiber (NDF) did not differ between treatments.Daily average intake of acid detergent fiber (ADF) and crude fiber (CF) were higher for treatment one. Animals submmitted to voluntary intake, showed higher nutrients average intake than the ones fed diet with $60 \%$ oat hay $+40 \%$ pea. There was no significant difference between both feeding systems to ADC of DM, nitrogen free extract (NFE) and crude protein (CP). However, ADC of organic matter (OM), ADF, NDF and CF were higher in restrict intake. There was higher ADC of DM, NFE, OM and CP in treatment two and there was no differences between treatments to ADC and NDF and CF.
\end{abstract}

Key Words: apparent digestibility, restrict intake, ruminant, voluntary intake

\section{Introdução}

A aveia (Avena sativa L.) é uma gramínea anual, originária da Ásia e sudeste europeu, adaptada para produzir em regiões de clima temperado. Os principais produtores são a Rússia, os Estados Unidos da América, Alemanha, Canadá e Polônia (Hartmann et al., 1988). No Brasil, a aveia é amplamente cultivada nos estados da região sul, sendo que no Paraná, é cultivada em todo o Estado (Monteiro et al., 1996), principalmente para alimentação animal, devido à facilidade de cultivo e ao bom valor nutricional da planta e dos grãos (Hartmann et al., 1988), proporcionando forragem muito tenra, palatável e nutritiva para os animais de qualquer idade (Pupo, 1981). Alcântara (1980) relatou que a aveia produz em torno

\footnotetext{
${ }^{1}$ Professores do Departamento de Zootecnia. Centro de Ciências Agrárias. Universidade Estadual de Londrina. Campus Universitário. Londrina, PR. CEP 86051-990. E.mail: mizubuti54@ hotmail.com; mizubuti@uel.br

${ }^{2}$ Pesquisador do Instituto Agronômico do Paraná (IAPAR).

${ }^{3}$ Médica Veterinária. Acadêmica do Programa de Pós-Graduação em Ciência Animal. Universidade Estadual de Londrina, Londrina, PR. ${ }^{4}$ Médico Veterinário.
} 
de 4,8 a 6,0 toneladas de matéria seca/ha de acordo com o cultivar. Monteiro et al., (1996), descreveram que em condições de média fertilidade, na região de Ponta Grossa, Paraná, o rendimento total de matéria seca de aveia submetidas a cortes no estádio vegetativo superou 5 t/ha durante a estação de crescimento.

Segundo Pupo (1981) e EMBRAPA (1991), o feno de aveia possui de 89,19 a $89,90 \%$ de matéria seca (MS), e apresenta a seguinte composição química $(\%)$, em base seca: proteína bruta $(\mathrm{PB})=5,30$ a 8,38; extrato etéreo $(\mathrm{EE})=1,90$ a 4,01; fibra bruta $(\mathrm{FB})=25,00$ a 30,60; extrato não nitrogenado $(\mathrm{ENN})$ $=30,60$ a 54,70; matéria mineral $(\mathrm{MM})=2,34$ a 7,50; cálcio $(\mathrm{Ca})=0,06$ a 0,30 e fósforo total $(\mathrm{P})=0,32 \mathrm{a}$ 0,38 .

De maneira geral, as alterações da composição química que ocorrem com o crescimento das plantas forrageiras são devidas principalmente aos aumentos nos teores de fibra bruta e diminuição no conteúdo celular em função das alterações na relação folha/caule (Crowder et al., 1967; Cherney \& Marten, 1982a, b).

A ervilha (Pisum sativum L.) é uma leguminosa originada na Etiópia, algumas áreas do mediterrâneo e Ásia central, se adaptando bem a temperaturas entre 13 e $18^{\circ} \mathrm{C}$ (Hartmann et al., 1988). No Brasil, os principais produtores de ervilha são os estados da região sul, sendo que um bom cultivar apresenta produtividade média de 2,2 a 2,7 toneladas de grãos secos/ha (Filgueira, 1981).

A produção de grãos e a composição química das leguminosas estão na dependência do cultivar, da localização geográfica e das condições de crescimento. Em geral, as leguminosas contêm de 20 a $30 \%$ de proteínas (Salunkhe et al., 1985; Waldroup \& Smith, 1989).

Segundo Gueguen (1991), o grão integral de ervilha pode conter de 18 a 30\% de PB. Grosjean (1985) apresentou a seguinte composição química (\%) em base seca: $\mathrm{PB}=25,00 ; \mathrm{EE}=1,80 ; \mathrm{FB}=6,10 ; \mathrm{MM}=3,50$; $\mathrm{ENN}=63,60$; Ptotal $=0,40 ; \mathrm{Ca}=0,10$; fibra em detergente ácido $(\mathrm{FDA})=8,40$ e fibra em detergente neutro $(\mathrm{FDN})=14,30$.

Verificou-se pela literatura consultada que diversos pesquisadores estudaram o valor nutritivo do feno de aveia, como a composição química e/ou digestibilidade dos nutrientes (Roston \& Andrade, 1992; Pereira et al., 1993; Reis et al., 1993; Lopez \& Muhlbach, 1994; Elizalde et al., 1994; Zebrowska et al., 1997; Hosoya et al., 1998), bem como o efeito da associação de feno de aveia a diferentes fontes

R. Bras. Zootec., v.31, n.2, p.1042-1049, 2002 (suplemento) protéicas, como: soja (Pereira et al., 1989), amônia anidra (Ferreira et al., 1993); amônia anidra ou uréia (Grossi et al., 1993); soja crua (Zeoula et al., 1994); canola (Prado et al., 1995); LabLab + milho (Nsahlai \& Umunna, 1996), entre outros. Entretanto, foram encontrados poucos trabalhos utilizando-se de grãos de ervilha (Pisum sativum L.) como objeto de estudo em avaliações biológicas com ruminantes.

Considerando a disponibilidade e a composição química do feno de aveia (Avena sativa L.) e ervilha (Pisum sativum L.) na região, este trabalho foi conduzido com os objetivos de determinar o consumo médio e o coeficiente de digestibilidade aparente dos nutrientes do feno de aveia e da ervilha, bem como de avaliar o balanço de nitrogênio em ovinos submetidos a dois regimes alimentares.

\section{Material e Métodos}

O ensaio de digestibilidade aparente, adotando-se o método de coleta total de fezes, foi conduzido no Laboratório de Metabolismo Animal do Departamento de Zootecnia, da Universidade Estadual de Londrina. Foram utilizados 10 ovinos machos, castrados, com peso médio de $36,64 \mathrm{~kg}$, distribuídos aleatoriamente em gaiolas metabólicas apropriadas, dotadas de cochos individuais para alimento e mistura mineral, bebedouro e coletor de urina.

O delineamento experimental utilizado foi o inteiramente casualizado com dois tratamentos e cinco repetições, sendo: $\mathrm{T} 1=$ ração com $80 \%$ de feno de aveia (Avena sativa L.) e $20 \%$ de ervilha (Pisum sativum $\mathrm{L}$.) e T2= ração com $60 \%$ de feno de aveia e $40 \%$ de ervilha .Os tratamentos foram avaliados sob dois regimes alimentares (consumo voluntário e restrito).

O ensaio compreendeu um período de adaptação de 15 dias, seguido de dois períodos de coleta de 7 dias cada. No período de adaptação, foi determinado o consumo voluntário individual. No primeiro período de coleta, foi medida a digestibilidade em condições de consumo voluntário e no segundo período, em condições de consumo restrito, este último foi calculado em função do tamanho metabólico $\left(\mathrm{kg} \mathrm{PV}^{0,75}\right)$, de maneira que o consumo fosse da ordem de $90 \%$ do menor consumo obtido nos últimos três dias do período de adaptação.

O feno de aveia foi confeccionado na Fazenda Escola da Universidade Estadual de Londrina e a ervilha, fornecida pelo Instituto Agronômico do Paraná. 
As composições químicas dos ingredientes das rações experimentais, bem como as proporções desses ingredientes nas rações, estão apresentadas nas Tabelas 1 e 2, respectivamente.

A ração foi fornecida em 2 refeições diárias, às 8 e $17 \mathrm{~h}$, cada qual contendo a metade da quantidade de alimento fornecido/dia. Água e sal mineral foram fornecidos à vontade em cochos apropriados.

A coleta de fezes foi efetuada uma vez ao dia, às $7 \mathrm{~h} 30$, por intermédio das bolsas coletoras, que permaneceram nos animais durante os períodos de adaptação e de coleta. As fezes foram pesadas diariamente (individual) e $20 \%$ do total excretado foram colocados em saco plástico e armazenado sob refrigeração para posterior análise. Para a coleta de urina, foram colocados diariamente nos recipientes coletores $20 \mathrm{~mL}$ de $\mathrm{HCl}$ 1:1, para evitar a fermentação e perdas de amônia por volatilização. Uma alíquota de urina

Tabela 1 - Composição química dos ingredientes das rações na base da matéria natural $(\mathrm{MN})$ e matéria seca $(\mathrm{MS})^{1}$

Table 1 - Chemical composition of ingredients used in the rations, in natural (NM) and dry matter (DM) basis ${ }^{1}$

\begin{tabular}{|c|c|c|c|c|}
\hline \multirow{3}{*}{$\begin{array}{l}\text { Componentes (\%) } \\
\text { Components (\%) }\end{array}$} & \multicolumn{2}{|c|}{$\begin{array}{c}\text { Feno de aveia } \\
\text { Oat hay }\end{array}$} & \multicolumn{2}{|c|}{$\begin{array}{c}\text { Ervilha } \\
\text { Pea }\end{array}$} \\
\hline & $\mathrm{MN}$ & MS & $\mathrm{MN}$ & MS \\
\hline & $N M$ & $D M$ & $N M$ & $D M$ \\
\hline Matéria seca & 84,92 & 100,00 & 89,25 & 100,00 \\
\hline Dry matter & & & & \\
\hline $\begin{array}{l}\text { Matéria orgânica } \\
\text { Organic matter }\end{array}$ & 76,95 & 90,61 & 86,78 & 97,23 \\
\hline $\begin{array}{l}\text { Proteína bruta } \\
\text { Crude protein }\end{array}$ & 7,68 & 9,04 & 20,40 & 22,86 \\
\hline $\begin{array}{l}\text { Extrato etéreo } \\
\text { Ether extract }\end{array}$ & 0,70 & 0,82 & 0,70 & 0,79 \\
\hline $\begin{array}{l}\text { Fibra bruta } \\
\text { Crude fiber }\end{array}$ & 30,19 & 35,55 & 5,55 & 6,22 \\
\hline $\begin{array}{l}\text { Fibra em detergente ácido } \\
\text { Acid detergentfiber }\end{array}$ & 36,62 & 43,13 & 7,28 & 8,16 \\
\hline $\begin{array}{l}\text { Fibra em detergente neutro } \\
\text { Neutral detergentfiber }\end{array}$ & 59,27 & 69,80 & 22,96 & 25,73 \\
\hline $\begin{array}{l}\text { Extrato não nitrogenado } \\
\text { Nitrogen free extract }\end{array}$ & 38,38 & 45,20 & 60,13 & 67,36 \\
\hline $\begin{array}{l}\text { Cinzas } \\
\text { Ash }\end{array}$ & 7,97 & 9,39 & 2,47 & 2,77 \\
\hline $\begin{array}{l}\text { Cálcio } \\
\text { Calcium }\end{array}$ & 0,45 & 0,53 & 0,13 & 0,15 \\
\hline $\begin{array}{l}\text { Fósforo } \\
\text { Phosphorus }\end{array}$ & 0,12 & 0,14 & 0,29 & 0,33 \\
\hline
\end{tabular}

${ }^{1}$ Dados obtidos no Laboratório de Nutrição Animal do Departamento de Zootecnia da Universidade Estadual de Londrina.

1 Data obtained at the Animal Nutrition Laboratory of the Animal Science Department, State University of Londrina.

\section{R. Bras. Zootec., v.31, n.2, p.1042-1049, 2002 (suplemento)}

correspondente a $10 \%$ do volume diário recolhido/ animal, foi armazenada a $-15^{\circ} \mathrm{C}$ para análise.

As amostras de ração, correspondendo a $10 \%$ do total fornecido diariamente, foram obtidas a cada fornecimento. As rações rejeitadas também foram pesadas, amostradas e armazenadas para posterior análise.

Para as análises laboratoriais, as amostras diárias, foram reunidas em amostras compostas/animal/tratamento e as determinações químicas, realizadas conforme metodologias descritas por AOAC (1990 a,b) e Silva (1981).

A análise estatística dos dados foi realizada utilizando-se o programa SAS (1995), sendo que as variáveis consideradas foram analisadas conforme o seguinte modelo matemático:

$$
\mathrm{Y}_{\mathrm{ijk}}=\mu+\mathrm{T}_{\mathrm{i}}+\mathrm{C}_{\mathrm{j}}+(\mathrm{TC})_{\mathrm{ij}}+\mathrm{e}_{\mathrm{ijk}}
$$

em que: $Y_{i j k}=$ observação $\mathrm{k}$, no animal submetido o nível de consumo $\mathrm{j}$ e tratamento $\mathrm{i} ; \mu=$ média geral;

Tabela 2 - Composição química das rações utilizadas nos tratamentos 1 e 2 , com base na matéria seca

Table 2 - Chemical composition of rations used in treatment 1 and 2, in dry matter basis

\begin{tabular}{|c|c|c|}
\hline \multirow[t]{2}{*}{$\begin{array}{l}\text { Componentes }(\%) \\
\text { Components }\end{array}$} & \multicolumn{2}{|c|}{$\begin{array}{l}\text { Tratamento } \\
\text { Treatment }\end{array}$} \\
\hline & $\mathrm{T} 1$ & $\mathrm{~T} 2$ \\
\hline Matéria seca & 100,00 & 100,00 \\
\hline Dry matter & & \\
\hline Matéria orgânica & 91,93 & 93,26 \\
\hline Organic matter & & \\
\hline Proteína bruta & 11,80 & 14,57 \\
\hline Crude protein & & \\
\hline Extrato etéreo & 0,81 & 0,81 \\
\hline Ether extract & & \\
\hline Fibra bruta & 29,68 & 23,82 \\
\hline Crude fiber & & \\
\hline $\begin{array}{l}\text { Fibra em detergente ácido } \\
\text { Acid detergentfiber }\end{array}$ & 36,14 & 29,14 \\
\hline $\begin{array}{l}\text { Fibra em detergente neutro } \\
\text { Neutral detergent fiber }\end{array}$ & 60,99 & 52,17 \\
\hline $\begin{array}{l}\text { Extrato não nitrogenado } \\
\text { Nitrogen free extract }\end{array}$ & 49,63 & 54,06 \\
\hline Cinzas & 8,10 & 6,74 \\
\hline Ash & & \\
\hline Cálcio & 0,45 & 0,38 \\
\hline Calcium & & \\
\hline Fósforo & 0,18 & 0,22 \\
\hline Phosphorus & & \\
\hline
\end{tabular}

$\mathrm{T} 1=80 \%$ de feno de aveia $+20 \%$ de ervilha.

$\mathrm{T} 2=60 \%$ de feno de aveia $+40 \%$ de ervilha.

$T 1=80 \%$ oat hay $+20 \%$ pea.

$T 2=60 \%$ oat hay $+40 \%$ pea. 
$\mathrm{T}_{\mathrm{i}}=$ efeito do tratamento $\mathrm{i} ; \mathrm{C}_{\mathrm{j}}=$ efeito do nível de consumo $\mathrm{j} ;(\mathrm{TC})_{\mathrm{ij}}=$ efeito da interação tratamento $\mathrm{x}$ consumo; $\mathrm{e}_{\mathrm{ijk}}=$ erro aleatório associado a cada observação.

Os coeficientes de digestibilidade dos nutrientes do feno de aveia e de ervilha foram estimados por intermédio do sistema de equações citado por Silva \& Leão (1979).

\section{Resultados e Discussão}

\section{Consumo médio diário}

$\mathrm{Na}$ Tabela 3 são apresentados os valores de consumo médio diário (CMD) de alguns nutrientes pelos animais submetidos aos diferentes tratamentos e regimes de consumo. Observou-se que não houve diferença significativa $(\mathrm{P}>0,05)$ no $\mathrm{CMD}$ de matéria seca (MS) e fibra em detergente neutro (FDN) entre os tratamentos.

O CMD de MS em g/kgPV ${ }^{0,75}$, encontrado neste trabalho para T1 $(53,56)$ e T2 $(56,77)$, foi semelhante àquele encontrado por Umunna et al. (1995), que

Tabela 3 - Consumo médio diário (CMD) de matéria seca (MS), fibra em detergente ácido (FDA), fibra em detergente neutro (FDN) e fibra bruta (FB) nos diferentes tratamentos e consumos

Table 3 - Daily average intake (DAl) of dry matter (DM), acid detergent fiber (ADF), neutral detergent fiber $(N D F)$ and crude fiber (CF) in different treatments and feed intakes

\begin{tabular}{lcccc}
\hline & \multicolumn{4}{c}{ Consumo médio diário $\left(\mathrm{g} / \mathrm{kgPV}^{0,75}\right)$} \\
& Daily average intake & $\left(\mathrm{g} / \mathrm{kg} \mathrm{W} B^{0.75}\right)$ \\
\cline { 2 - 5 } Tratamento (T) & $\mathrm{MS}$ & $\mathrm{FDA}$ & $\mathrm{FDN}$ & $\mathrm{FB}$ \\
Treatment $(T)$ & $D M$ & $A D F$ & $N D F$ & $C F$ \\
\hline 1 & $53,56^{\mathrm{A}}$ & $17,73^{\mathrm{A}}$ & $32,02^{\mathrm{A}}$ & $15,01^{\mathrm{A}}$ \\
2 & $56,77^{\mathrm{A}}$ & $14,24^{\mathrm{B}}$ & $28,76^{\mathrm{A}}$ & $12,00^{\mathrm{B}}$ \\
$\mathrm{CV}(\%)$ & 12,37 & 17,71 & 15,41 & 14,83 \\
Consumo & & & & \\
Intake & & & & \\
Voluntário & $9,15^{\mathrm{A}}$ & $22,34^{\mathrm{A}}$ & $43,36^{\mathrm{A}}$ & $18,85^{\mathrm{A}}$ \\
Voluntary & & & & \\
Restrito & $31,19^{\mathrm{B}}$ & $9,64^{\mathrm{B}}$ & $17,21^{\mathrm{B}}$ & $8,37^{\mathrm{B}}$ \\
Restrict & & & & \\
CV $(\%)$ & 12,37 & 17,71 & 15,41 & 14,83 \\
\hline
\end{tabular}

Médias seguidas de letras diferentes na coluna, diferem entre si $(P<0,05)$ pelo teste de Tukey.

$\mathrm{T} 1=80 \%$ de feno de aveia $+20 \%$ de ervilha.

$\mathrm{T} 2=60 \%$ de feno de aveia $+40 \%$ de ervilha.

$\mathrm{CV}=$ Coeficiente de variação.

Means followed by different letter within a column, differ by Tukey test $(P<.05)$.

$T 1=80 \%$ oat hay $+20 \%$ pea.

$T 2=60 \%$ oat hay $+40 \%$ pea.

$\mathrm{CV}=$ Coefficient of variation.

R. Bras. Zootec., v.31, n.2, p.1042-1049, 2002 (suplemento) relataram valores de CMD de 55,9 g de MS de feno de aveia suplementado com Lablab (Lablab purpureous). Da mesma forma, Lopez \& Muhlbach (1994), trabalhando com forragem de aveia, e Becker et al. (1995), com aveia preta, relataram valores de CMD de MS de 58,89 e $52,47 \mathrm{~g} / \mathrm{kgPV}^{0,75}$, respectivamente.

$\mathrm{O}$ CMD de fibra em detergente ácido (FDA) e fibra bruta $(\mathrm{FB})$ foram maiores $(\mathrm{P}<0,05)$ para o tratamento 1 (Tabela 3). Isto é explicado pelo fato de os animais submetidos ao $\mathrm{T} 1$ receberem ração com mais FB $(29,68 \%)$ e FDA $(36,14)$ que aqueles submetidos ao T2 (23,82 e $29,14 \%$, respectivamente).

Como era esperado, observou-se maior CMD de MS, FDA, FDN e FB para os animais sob regime de consumo voluntário (Tabela 3).

Houve interações (Tabela 4 ) entre os regimes de consumo e tratamentos para CMD de extrato nãonitrogenado (ENN), matéria orgânica (MO), extrato etéreo (EE) e proteína bruta $(\mathrm{PB})$, constatando-se que o CMD de ENN, MO, EE e PB foi maior $(\mathrm{P}<0,05)$ para animais submetidos ao consumo voluntário, independentemente dos tratamentos. Para animais sob regime de consumo voluntário, as médias de consumo desses nutrientes foram maiores $(\mathrm{P}<0,05)$ para aqueles recebendo ração com $60 \%$ de feno $+40 \%$ de ervilha (Tabela 4).

$\mathrm{O}$ valor de $10,38 \mathrm{~g}$ de $\mathrm{PB} / \mathrm{kgPV}^{0,75}$ encontrado neste trabalho, para o tratamento $1(80 \%$ feno de aveia $+20 \%$ ervilha) com animais em regime de consumo voluntário está próximo daquele apresentado por Zeoula et al. (1994), que obtiveram CMD de $\mathrm{PB}$ de $9,1 \mathrm{~g} / \mathrm{kgPV}^{0,75}$ para animais consumindo ração contendo $80 \%$ de feno de aveia e $20 \%$ de soja, e mantidos em regime de consumo voluntário.

Pereira et al. (1993), trabalhando com três forrageiras (aveia, sorgo e milheto) obtiveram CMD $\left(\mathrm{g} / \mathrm{kgPV}^{0,75}\right)$ de MS, MO e PB de 31,2; 24,9 e 5,7, respectivamente, para animais alimentados com aveia. Da mesma forma, Becker et al. (1995), comparando CMD de feno de aveia preta e silagem, observaram maior CMD de MS e MO (52,47 e 29,46 g/kgPV ${ }^{0,75}$, respectivamente) em animais recebendo feno de aveia preta. Por outrolado, Umunnaetal. (1995), trabalhandocomfeno de aveia e feno de aveia suplementada com Lablab (Lablab purpureous), encontraram maiores valores de CMD de MO (57,2 e 68,5 g/kgPV ${ }^{0,75}$, respectivamente) para os animais recebendo feno suplementado.

Os CMD obtidos neste experimento, quando comparados àqueles relatados por outros pesquisadores, sugerem variação nos níveis de consumo de diferentes 
nutrientes conforme o tipo e a qualidade do alimento ingerido pelos animais, bem como a sua associação com alimentos concentrados.

\section{Coeficiente de digestibilidade aparente}

Não se observou diferença significativa nos coeficientes de digestibilidade aparente (CDA) da MS, ENN e $\mathrm{PB}$ entre os consumos voluntário e restrito, entretanto, houve maior CDA da MO, FDA, FDN e FB das rações em animais submetidos ao consumo restrito (Tabela 5). Zeoula et al. (1994) também observaram maior CDA da MO, ENN e FB de ração à base de soja crua e feno de aveia nos animais submetidos ao consumo restrito.

Provavelmente, o menor nível de consumo de alimento proporciona maior tempo de permanência deste alimento no rúmem, melhorando a fermentação e, conseqüientemente, o coeficiente de digestibilidade de alguns nutrientes.

Observou-se maior $(\mathrm{P}<0,05) \mathrm{CDA}$ da MS, ENN, MO e PB para o tratamento 2 e maior CDA de FDA para o tratamento 1 . Não se observaram diferenças significativas $(\mathrm{P}>0,05)$ no $\mathrm{CDA}$ de $\mathrm{FDN}$ e FB entre os dois tratamentos (Tabela 5).

Os valores de CDA de FB e FDN encontrados no tratamento 2 deste ensaio foram semelhantes àqueles encontrados por Prado et al. (1995) para o feno de aveia, cujos coeficientes variaram de 57,80 a $61,80 \%$ e 56,10 a $58,50 \%$, respectivamente.

Os CDA da MS, ENN, FB, PB, FDN e FDA do tratamento 1 (Tabela 5) foram semelhantes àqueles encontrados por diferentes pesquisadores (Roston \& Andrade, 1992; López \& Mühlbach, 1994; Becker et al., 1995; Rodríguez et al., 1997; e Kraiem et al., 1997).

Os aumentos verificados nos CDA da MS, ENN, MO e PB do tratamento 2 (Tabela 5) são, provavelmente, conseqüência da elevação do conteúdo celular e da concomitante redução da proporção de parede celular (FDA), à medida que se aumentou a proporção de concentrado na ração.

De maneira geral, os CDA da MS, MO, FDA e PB das rações observados neste trabalho, considerando os tratamentos e os níveis de consumo alimentar, foram similares àqueles apresentados por Kraiem et al. (1997).

Houve interação entre o nível de consumo e tratamento para o CDA do EE (Tabela 6). Verificou-se maior CDA do EE da ração do tratamento 2 nos animais sob regime de consumo voluntário. Observou-se maior CDA do EE das rações do tratamento 1 para os animais submetidos ao consumo restrito.
Tabela 4 - Média das interações entre consumos e tratamentos para consumo médio diário (CMD) de extrato não nitrogenado (ENN), matéria orgânica (MO), extrato etéreo (EE) e proteína bruta (PB) em g/kgPV 0,75

Table 4 - Interaction average between feed intake and treatment for daily average intake (DAÍ) of nitrogen free extract (NFE), organic matter $(O M)$, ether extract $(E E)$ and crude protein $(C P)$ in $\mathrm{g} / \mathrm{kgWB} \mathrm{B}^{0.75}$

\begin{tabular}{|c|c|c|}
\hline $\begin{array}{l}\text { Tratamento } \\
\text { Treatment }\end{array}$ & \multicolumn{2}{|c|}{$\begin{array}{c}\text { Extrato não nitrogenado } \\
\text { Nitrogen free extract }\end{array}$} \\
\hline & \multicolumn{2}{|c|}{$\begin{array}{l}\text { Consumo } \\
\text { Feed intake }\end{array}$} \\
\hline & $\begin{array}{l}\text { Voluntário } \\
\text { Voluntary }\end{array}$ & $\begin{array}{r}\text { Restrito } \\
\text { Restrict }\end{array}$ \\
\hline $\begin{array}{l}1 \\
2 \\
\mathrm{CV}(\%) \\
\end{array}$ & $\begin{array}{l}37,13^{\mathrm{Ba}} \\
44,41^{\mathrm{Aa}} \\
11,84\end{array}$ & $\begin{array}{l}15,63^{\mathrm{Ab}} \\
15,73^{\mathrm{Ab}} \\
11,84\end{array}$ \\
\hline $\begin{array}{l}\text { Tratamento } \\
\text { Treatment }\end{array}$ & \multicolumn{2}{|c|}{ Matéria orgânica } \\
\hline & \multicolumn{2}{|c|}{$\begin{array}{c}\text { Consumo } \\
\text { Feedintake } \\
\end{array}$} \\
\hline & $\begin{array}{l}\text { Voluntário } \\
\text { Voluntary }\end{array}$ & $\begin{array}{r}\text { Restrito } \\
\text { Restrict }\end{array}$ \\
\hline $\begin{array}{l}1 \\
2 \\
\mathrm{CV}(\%)\end{array}$ & $\begin{array}{l}68,70^{\mathrm{Ba}} \\
78,50^{\mathrm{Aa}} \\
12,06\end{array}$ & $\begin{array}{l}30,08^{\mathrm{Ab}} \\
27,82^{\mathrm{Ab}} \\
12,06\end{array}$ \\
\hline \multirow[t]{3}{*}{ Treatment } & \multicolumn{2}{|c|}{$\begin{array}{c}\text { Extrato etéreo } \\
\text { Ether extract }\end{array}$} \\
\hline & \multicolumn{2}{|c|}{$\begin{array}{c}\text { Consumo } \\
\text { Feedintake }\end{array}$} \\
\hline & $\begin{array}{l}\text { Voluntário } \\
\text { Voluntary }\end{array}$ & $\begin{array}{r}\text { Restrito } \\
\text { Restrict }\end{array}$ \\
\hline $\begin{array}{l}1 \\
2 \\
\mathrm{CV}(\%)\end{array}$ & $\begin{array}{l}0,98^{\mathrm{Ba}} \\
1,62^{\mathrm{Aa}} \\
6,83\end{array}$ & $\begin{array}{l}0,57^{\mathrm{Ab}} \\
0,51^{\mathrm{Ab}} \\
6,83\end{array}$ \\
\hline \multirow[t]{3}{*}{ Treatment } & \multicolumn{2}{|c|}{$\begin{array}{l}\text { Proteína bruta } \\
\text { Crude protein }\end{array}$} \\
\hline & \multicolumn{2}{|c|}{$\begin{array}{l}\text { Consumo } \\
\text { Feed intake }\end{array}$} \\
\hline & $\begin{array}{l}\text { Voluntário } \\
\text { Voluntary }\end{array}$ & $\begin{array}{l}\text { Restrito } \\
\text { Restrict }\end{array}$ \\
\hline $\begin{array}{l}1 \\
2 \\
\mathrm{CV}(\%)\end{array}$ & $\begin{array}{c}10,38^{\mathrm{Ba}} \\
15,34^{\mathrm{Aa}} \\
9,97\end{array}$ & $\begin{array}{l}4,10^{\mathrm{Ab}} \\
4,62^{\mathrm{Ab}} \\
9,97\end{array}$ \\
\hline
\end{tabular}

Médias seguidas de mesma letra, maiúscula na coluna e minúscula na linha, não diferem $(P>0,05)$ pelo teste Tukey.

$\mathrm{T} 1=80 \%$ de feno de aveia $+20 \%$ de ervilha.

$\mathrm{T} 2=60 \%$ de feno de aveia $+40 \%$ de ervilha.

$\mathrm{CV}=$ Coeficiente de variação.

Means within a column, followed by same capital letter and within a row, followed by same small letter, do not differ by Tukey test $(P>.05)$.

$T 1=80 \%$ oat hay $+20 \%$ pea.

$T 2=60 \%$ oat hay $+40 \%$ pea.

$\mathrm{CV}=$ Coefficient of variation. 
Tabela 5 - Coeficiente de digestibilidade aparente (CDA) da matéria seca (MS), extrato não nitrogenado (ENN), matéria orgânica (MO), proteína bruta (PB), fibra em detergente ácido (FDA), fibra em detergente neutro (FDN) e fibra bruta (FB) para os diferentes consumos e tratamentos

Table 5 - Apparent digestibility coefficient (ADC) of dry matter (DM), nitrogen free extract (NFE), organic matter (OM), crude protein $(C P)$, acid detergent fiber (ADF), neutral detergent fiber (NDF) and crude fiber (CF) for different feeding systems and treatments

\begin{tabular}{|c|c|c|c|c|c|c|c|}
\hline \multirow[b]{2}{*}{$\begin{array}{l}\text { Consumo } \\
\text { Intake }\end{array}$} & \multicolumn{7}{|c|}{$\begin{array}{c}\text { Coeficiente de digestibilidade aparente }(\%) \\
\text { Apparent digestibility coefficient }(\%)\end{array}$} \\
\hline & $\begin{array}{l}\text { MS } \\
D M\end{array}$ & $\begin{array}{l}\text { ENN } \\
N F E\end{array}$ & $\begin{array}{l}\mathrm{MO} \\
O M\end{array}$ & $\begin{array}{l}\mathrm{PB} \\
C P\end{array}$ & $\begin{array}{l}\text { FDA } \\
A D F\end{array}$ & $\begin{array}{l}\mathrm{FDN} \\
N D F\end{array}$ & $\begin{array}{l}\mathrm{FB} \\
C F\end{array}$ \\
\hline $\begin{array}{l}\text { Voluntário } \\
\text { Voluntary }\end{array}$ & $58,49^{\mathrm{A}}$ & $62,30^{A}$ & $62,01^{\mathrm{B}}$ & $69,16^{\mathrm{A}}$ & $42,55^{\mathrm{B}}$ & $55,33^{\mathrm{B}}$ & $55,87^{\mathrm{B}}$ \\
\hline $\begin{array}{l}\text { Restrito } \\
\text { Restrict }\end{array}$ & $61,67^{\mathrm{A}}$ & $65,26^{\mathrm{A}}$ & $66,02^{\mathrm{A}}$ & $68,52^{\mathrm{A}}$ & $47,84^{\mathrm{A}}$ & $60,15^{\mathrm{A}}$ & $64,04^{\mathrm{A}}$ \\
\hline $\begin{array}{l}\mathrm{CV}(\%) \\
\text { Tratamento }\end{array}$ & 6,19 & 5,68 & 5,22 & 4,38 & 9,96 & 6,59 & 9,84 \\
\hline $\begin{array}{l}\text { Treatment } \\
1 \\
2 \\
\mathrm{CV}(\%)\end{array}$ & $\begin{array}{c}57,35^{\mathrm{B}} \\
62,81^{\mathrm{A}} \\
6,19\end{array}$ & $\begin{array}{c}60,17^{\mathrm{B}} \\
67,40^{\mathrm{A}} \\
5,68\end{array}$ & $\begin{array}{c}61,37^{\mathrm{B}} \\
66,66^{\mathrm{A}} \\
5,22\end{array}$ & $\begin{array}{c}65,05^{\mathrm{B}} \\
72,64^{\mathrm{A}} \\
4,38\end{array}$ & $\begin{array}{c}47,44^{\mathrm{A}} \\
42,95^{\mathrm{B}} \\
9,96\end{array}$ & $\begin{array}{c}57,35^{\mathrm{A}} \\
58,12^{\mathrm{A}} \\
6,59\end{array}$ & $\begin{array}{c}60,85^{\mathrm{A}} \\
59,06^{\mathrm{A}} \\
9,84\end{array}$ \\
\hline
\end{tabular}

Médias seguidas de letras diferentes na coluna, diferem entre si $(P<0,05)$ pelo teste Tukey.

$\mathrm{T} 1=80 \%$ de feno de aveia $+20 \%$ de ervilha.

$\mathrm{T} 2=60 \%$ de feno de aveia $+40 \%$ de ervilha.

$\mathrm{CV}=$ Coeficiente de variação (Coeficient of variation)

Means followed by different letter within a column, differ by Tukey test $(P<.05)$.

$T 1=80 \%$ oat hay $+20 \%$ pea.

$T 2=60 \%$ oat hay $+40 \%$ pea.

O balanço de nitrogênio (BN) dos animais que receberam ração com maior teor de ervilha $(27,98 \mathrm{~g}$ $\mathrm{N} /$ dia) foi superior aos daqueles que receberam menor proporção de ervilha na ração (15,37 g N/dia), como mostra a Tabela 6. Segundo Zeoula et al. (1994), fato que se deve, em parte, à maior ingestão de PB proporcionada pelo alimento concentrado e pela maior digestibilidade da $\mathrm{PB}$ da ração.

$\mathrm{O} \mathrm{BN}$ dos animais sob regime de consumo restrito no tratamento 1 foi de $6,15 \mathrm{~g} / \mathrm{dia}$ e no tratamento 2 foi de $8,16 \mathrm{~g} /$ dia. Kraiem et al. (1997), trabalhando com feno de aveia e diferentes proporções de concentrado, observaram valores de BN variando de 6,52 a 15,24g/ dia, conforme as proporções de concentrado na ração.

Constam na Tabela 7 os coeficientes de digestibilidade aparente (CDA) de alguns nutrientes do feno de aveia e ervilha.

Verificou-se que o CDA da MS do feno de aveia, nos animais submetidos ao consumo restrito $(59,45 \%)$ foi semelhante àqueles relatados por Becker et al. (1995), que foi de 58,25\%. Entretanto, estão acima dos valores relatados por Umunna et al. (1995), Kraiem et al. (1997) e Lopez \& Mulhback (1994), cujos valores variaram de 50,40 a 55,90\%, e abaixo dos valores de 62,44 a 71,96\%, encontrados por Sridhar Rao \& Thakur (1993) e Singh \& Narang
Tabela 6 - Média das interações entre consumos e tratamentos para coeficiente de digestibilidade aparente (CDA) do extrato etéreo (EE) e para balanço de nitrogênio

Table 6 - Interaction average between feed intake and treatment for apparent digestibility coefficient (ADC) of ether extract $(E E)$ and for nitrogen balance

Tratamento Coeficiente de digestibilidade

Treatment aparente (\%) de extrato etéreo

Apparent digestibility

coefficient (\%) of ether extract

\begin{tabular}{llc}
\hline \multicolumn{2}{c}{ Consumo } \\
\cline { 2 - 3 } & \multicolumn{2}{c}{ Feed intake } \\
\cline { 2 - 3 } & Voluntário & Restrito \\
& Restrict \\
\hline 1 & $58,14^{\mathrm{Bb}}$ & $69,02^{\mathrm{Aa}}$ \\
2 & $73,86^{\mathrm{Aa}}$ & $69,62^{\mathrm{Aa}}$ \\
\hline
\end{tabular}

Tratamento Balanço de nitrogênio (g/dia) Treatment Nitrogen balance (g/day)

\begin{tabular}{ccc}
\hline & \multicolumn{3}{c}{ Consumo } \\
Feedintake \\
\cline { 2 - 4 } & Voluntário & Restrito \\
& Voluntary & Restrict \\
\hline 1 & $15,3693^{\mathrm{Ba}}$ & $6,1494^{\mathrm{Ab}}$ \\
2 & $27,9760^{\mathrm{Aa}}$ & $8,1635^{\mathrm{Ab}}$
\end{tabular}

Médias seguidas de mesma letra, maiúscula na coluna e minúscula na linha, não diferem $(P>0,05)$ pelo teste de Tukey. $\mathrm{T} 1=80 \%$ de feno de aveia $+20 \%$ de ervilha.

T2 $=60 \%$ de feno de aveia $+40 \%$ de ervilha.

Means within a column, followed by same capital letter and within a row, followed bythe same small letter, do not differ $(P>.05)$ by Tukey test.

$T 1=80 \%$ oat hay $+20 \%$ pea.

$T 2=60 \%$ oat hay $+40 \%$ pea. 
Tabela 7 - Coeficiente de digestibilidade aparente (CDA) da matéria seca (MS), matéria orgânica (MO), proteína bruta (PB), fibra em detergente neutro (FDN), extrato etéreo (EE) e extrato não nitrogenado (ENN) da ervilha e do feno de aveia nos diferentes regimes de consumo alimentar

Table 7 - Apparent digestibility coefficient (ADC) of dry matter (DM), organic matter (OM), crude protein (CP), neutral detergent fiber (NDF), ether extract (EE) and nitrogen free extract (NFE) of oat hay and pea for different feeding systems

\begin{tabular}{|c|c|c|c|c|c|c|c|}
\hline \multirow[t]{2}{*}{$\begin{array}{l}\text { Consumo } \\
\text { Intake }\end{array}$} & \multirow[t]{2}{*}{$\begin{array}{l}\text { Ingrediente } \\
\text { Ingredient }\end{array}$} & \multicolumn{5}{|c|}{$\begin{array}{c}\text { Coeficiente de digestibilidade aparente }(\%) \\
\text { Apparent digestibility coefficient }(\%)\end{array}$} & \multirow[b]{2}{*}{$\begin{array}{l}\text { ENN } \\
N F E \\
\end{array}$} \\
\hline & & $\begin{array}{l}\text { MS } \\
\text { DM }\end{array}$ & $\begin{array}{l}\mathrm{MO} \\
\mathrm{OM}\end{array}$ & $\begin{array}{l}\mathrm{PB} \\
C P\end{array}$ & $\begin{array}{l}\text { FDN } \\
N D F\end{array}$ & $\begin{array}{l}\mathrm{EE} \\
E E\end{array}$ & \\
\hline Voluntário & Ervilha & $662,58^{\mathrm{A}}$ & $64,02^{\mathrm{A}}$ & $72,05^{\mathrm{B}}$ & $42,95^{\mathrm{A}}$ & $81,45^{\mathrm{A}}$ & $65,50^{\mathrm{B}}$ \\
\hline $\begin{array}{l}\text { Voluntary } \\
\text { Restrito }\end{array}$ & $\begin{array}{l}\text { Pea } \\
\text { Ervilha }\end{array}$ & $663,01^{\mathrm{A}}$ & $76,86^{\mathrm{A}}$ & $83,01^{\mathrm{A}}$ & $44,21^{\mathrm{A}}$ & $70,83^{\mathrm{B}}$ & $82,27^{\mathrm{A}}$ \\
\hline $\begin{array}{l}\text { Restrict } \\
\text { Voluntário } \\
\text { Voluntary }\end{array}$ & $\begin{array}{l}P e a \\
\text { Feno de aveia }\end{array}$ & $339,86^{\mathrm{B}}$ & $43,17^{\mathrm{B}}$ & $45,42^{\mathrm{B}}$ & $42,41^{B}$ & $37,13^{\mathrm{B}}$ & $42,38^{\mathrm{B}}$ \\
\hline $\begin{array}{l}\text { Restrito } \\
\text { Restrict }\end{array}$ & $\begin{array}{l}\text { Feno de aveia } \\
\text { Oat hay }\end{array}$ & $559,45^{\mathrm{A}}$ & $61,14^{\mathrm{A}}$ & $57,67^{\mathrm{A}}$ & $62,25^{\mathrm{A}}$ & $68,92^{\mathrm{A}}$ & $54,56^{\mathrm{A}}$ \\
\hline
\end{tabular}

Médias seguidas de mesma letra na coluna, dentro de um mesmo ingrediente, não diferem entre si $(P>0,05)$ pelo teste Tukey. Means within a column in a same ingredient, followed by same letter, do not differ $(P>.05)$ by Tukey test.

(1992). O CDA da MO (61,13\%), PB (57,63\%) e FDN $(62,27 \%)$ do feno de aveia em animais sob regime de consumo restrito, estão dentro dos limites de variação encontrados na literatura, conforme os apresentados por Becker et al. (1995), Umunna et al. (1995), Kraiem et al. (1997), Singh \& Narang (1992) e Sridhar Rao \& Takur (1993), os quais foram de 52,10 a $71,96 \%$ para MO; 51,83 a 61,47 para PB e 61,53 a $67,52 \%$ para FDN. Da mesma forma, o CDA do $\operatorname{EE}(69,40 \%)$ e do $\operatorname{ENN}(54,54 \%)$ estão, respectivamente, dentro dos limites de variação apresentados por Sridhar Rao \& Takur (1993) que foram de 53,75 a $74,56 \%$ para EE e 69,23 a $70,24 \%$ para ENN.

Os CDA da MS, MO, PB e EE da ervilha encontrados nos animais submetidos ao consumo voluntário foram de 62,$52 ; 64,03 ; 72,05$; e $81,99 \%$; e nos animais em consumo restrito, 63,01; 76,88; 83,04 e 69,99\%, respectivamente. Waldroup \& Smith (1989) relataram valores de 66,$90 ; 71,50 ; 87,80$ e $86,80 \%$, respectivamente, para os CDA da MS, MO, PB e EE. SAroj \& Neelam (1994) e Henry \& Bourdon (1991) citados por Gueguen (1991), relataram CDA da PB variando de 60,40 a $88,00 \%$.

\section{Conclusões}

Animais alimentados com $80 \%$ de feno de aveia $+20 \%$ de ervilha apresentaram maior consumo médio diário de FDA e FB.

Os coeficientes de digestibilidade da MO, FDA,
FDN e FB das rações foram maiores nos animais submetidos ao consumo restrito.

Os coeficientes de digestibilidade da MS, ENN, MO e PB foram maiores na ração com $60 \%$ de feno de aveia e $40 \%$ de ervilha.

$\mathrm{O}$ balanço de nitrogênio dos animais que receberam ração com $40 \%$ de ervilha foi superior àqueles que receberam $20 \%$.

Os coeficientes de digestibilidade aparente do feno de aveia foram maiores nos animais submetidos ao consumo restrito.

Os coeficientes de digestibilidade dos nutrientes da ervilha foram maiores apenas para proteína bruta e extrato não nitrogenado, nos animais submetidos ao consumo restrito.

\section{Literatura Citada}

ASSOCIATION OF OFFICIAL ANALYTICAL CHEMISTS AOAC - Official methods of analysis. 15.ed. Arlington, Virgínia, 1990a. v.1, p.684.

ASSOCIATION OF OFFICIAL ANALYTICAL CHEMISTS AOAC - Official methods of analysis. 15.ed. Arlington, Virgínia, 1990b. v.2, p.685-1298.

ALCÂNTARA, P.B. Plantas forrageiras: gramíneas \& leguminosas. São Paulo: Nobel, 1980. 150p.

BECKER, A.E.; PRATES, E.R.; MÜHLBACH, P.R.F. Consumo e digestibilidade de silagens e feno de aveia preta (Avena strigosa $L$. ). Revista da Sociedade Brasileira de Zootecnia, v.24, n.6, p.1062-1070, 1995.

CHERNEY, I.H.; MARTEN, G.C. Small grain crop forage potencial. I. Biological and chemical determinants quality, and yield. Crop Science, v.22, p.227-231, 1982a.

CHERNEY, I.H.; MARTEN, G.C. Small grain crop forage potencial. II. Interrelationships among biological, chemical,

R. Bras. Zootec., v.31, n.2, p.1042-1049, 2002 (suplemento) 
morphological and anatomical determinant of quality. Crop Science, v.22, p.240-245, 1982 b.

CROWDER, L.V.; LOTERO, J.; FRANSEN, J. et al. Oat forage production in the cool tropics as represented by Colombia. Agronomy Journal, v.59, n.1, p.80-82, 1967.

ELIZALDE, J.C.; SANTINI, F.J.; PASINATO, A.M. The effect of stage of harvest on the processes of digestion in cattle fed winter oats indoors. 1. Digestion of organic matter, neutral detergent fibre and water soluble carbohydrates. Animal Feed Science and Techology, v.47, n.3-4, p.201-211, 1994.

EMPRESA BRASILEIRA DE PESQUISA AGROPECUÁRIA - EMBRAPA. Centro Nacional de Pesquisa de Suínos e Aves. Tabela de composição química de valores energéticos de alimentos para suínos e aves. 3.ed. Concórdia: 1991. 97p. (Documento, 19).

FERREIRA, J.Q.; GARCIA, R.; QUEIROZ, A.C. et al. Efeito dos níveis de amônia anidra e dos períodos pós-tratamento sobre a qualidade dos fenos de aveia contendo alta ou baixa umidade. Revista da Sociedade Brasileira de Zootecnia, v.22, n.1, p.47-52, 1993.

FILGUEIRA, F.A.R. Manual de olericultura: cultura e comercialização de hortaliças. 2.ed. São Paulo: Agronômica Ceres, 1981. 338p.

GROSJEAN, F. Combining peas for animal feed. In: HEBBLE THWAITE, P.D.; HEATH, M.C.; DAWKINS, T.C.K. (Eds.) The pea crop - a basis for improvement. London: Mid-County Press, 1985. p.453-462.

GROSSI, S.F.; REIS, R.A.; EZEQUIEL, J.M.B. et al. Tratamento de volumosos com amônia anidra ou uréia. Revista da Sociedade Brasileira de Zootecnia, v.22, n.4, p.651-660, 1993.

GUEGUEN, J. Pea and fababeans proteins. In: HUDSON, B.J.F. (Ed.) Developments in food proteins. London: Elsevier Applied Science, 1991. p.35-78.

HARTMANN, H.T.; KOFRANEK, A.M.; RUBATZKY, V.E. et al. Plant science: growth, development, and utilization of cultivated plants. 2.ed. Englewood Cliffs: 1988. 674p.

HOSOYA, H.; MITSUI, Y.; HOTTA, M. et al. Evaluation of variability in forage oats (avena sativa $L$.) varieties in regard to feed composition. Grassland Science, v.43, n.4, p.474-481, 1998.

KRAIEM, K.; MAJDOUB, A.; BEM ABBES, S. et al. Effects of the level of supplementation with concentrate on the nutritive value and utilization of oats hay cut at three maturity stages. Livestock Production Science, v.47, n.2, p.175-184, 1997.

LOPEZ, S.E.; MUHLBACH, P.R.F. Efeito de diferentes tratamentos no valor nutritivo da aveia branca (avena sativa $L$.) conservada na forma de silagem ou feno. Revista da Sociedade Brasileira de Zootecnia, v.23, n.4, p.519-526, 1994.

MONTEIRO, A.L.G.; MORAES, A.; CORREAA, E.A.S. et al. Forragicultura no Paraná. Londrina: Comissão Paranaense de Avaliação de Forrageiras, 1996. 291p.

NSAHLAI, I.V.; UMUNNA, N.N. Sesbania and Lablab supplementation of oat hay basal diet fed to sheep with or without maize grain. Animal Feed Science and Technology, v.61, n.1-4, p.275-289, 1996.

PEREIRA, J.C.; CARMO, M.B.; MOTTA, V.A.F. et al. Feno de aveia (Avena bizantyna, K. Koch) associado ao concentrado em diferentes proporções na alimentação de eqüinos. Revista da Sociedade Brasileira de Zootecnia, v.18, n.5, p.359-366, 1989.

PEREIRA, O.G.; OBEID, J.A.; GOMIDE, J.A. et al. Produtividade e valor nutritivo de aveia (avena sativa), milheto (Pennisetum americanum L.), e de um híbrido de sorghum bicolor X S. sudanense. Revista da Sociedade Brasileira de Zootecnia, v.22, n.1, p.22-30, 1993.
PRADO, I.N.; BRANCO, A.F.; ZEOULA, L.M. et al. Níveis e processamento da canola e tamanho da partícula do feno de aveia sobre o consumo voluntário e digestibilidade aparente em ovinos. Arquivo de Biologia e Tecnologia, v.38, n.2, p.441-452, 1995.

PUPO, N.I.H. Manual de pastagens e forrageiras. Campinas: Instituto Campineiro de Ensino Agrícola, 1981. 343p.

REIS, R.A.; RODRIGUES, L.R.A.; COAN, O. et al. Produção e qualidade da forragem de aveia (avena spp). Revista da Sociedade Brasileira de Zootecnia, v.22, n.1, p.99-109, 1993.

RODRÍGUEZ, L.R.R.; FONTES, C.A.A.; JORGE, A.M. et al. Digestibilidade de rações contendo quatro níveis de concentrado, em bovinos (Taurinos e Zebuínos) e bubalinos. Revista da Sociedade Brasileira de Zootecnia, v.26, n.4, p.844-851, 1997.

ROSTON, A.J.; ANDRADE, P. Digestibilidade de forrageiras com ruminantes: coletânea de informações. Revista da Sociedade Brasileira de Zootecnia, v.2, n.4, p.647-666, 1992.

SALUNKE, D.K.; KADAM, S.S.; CHAVAN, J.K. Postharvest biotechnology of food legumes. Florida: CRC Press, 1985. 160p.

SAROJ, B.; NEELAM, K. Protein digestibility of vegetables and field peas (Pisum sativum). Varietal differences and effect of domestic processing and cooking methods. Plant Foods for Human Nutrition, v.46, n.1, p.71-76, 1994.

SAS INSTITUTE. Statistical Analysis System. User's guide statistics. Version 6.10 edition. Cary: 1995. 956p.

SILVA, D.J. Análises de alimentos (métodos químicos e biológicos). Viçosa, MG: Universidade Federal de Viçosa, 1981. 166p.

SILVA, J.F.C.; LEÃO, M.I. Fundamentos de nutrição dos ruminantes. Piracicaba: Livroceres, 1979. 380p.

SINGH, B.; NARANG, M.P. Nutritive evaluation of Setaria anceps cv. Kazungula, S. anceps cv. Narok, Pennisetum clandestinum and Avena sativa forages. Indian Journal of Animal Science, v.62, n.1, p.63-68, 1992.

SRIDHAR RAO, G.; THAKUR, S.S. Rumen fermentation, digestibility of nutrients and degradability of different feed materials in calves fed unchaffed, chaffedand ground oat hay. Indian Journal of Animal Science, v.63, n.3, p.318-323, 1993.

UMUNNA, N.N.; OSUJI, P.O.; NSAHLAI, I.V. et al. Effect of supplementing oat hay with lablab, sesbania, tagasaste or wheat middlings on voluntary intake, $\mathrm{N}$ utilization and weigth gain of Ethiopian Menz sheep. Small Ruminants Research, v.18, n.2, p.113-120, 1995.

WALDROUP, P.W.; SMITH, K.J. Animal feed uses of legumes. In: MATTHEUS, R.H. (Ed.) Legumes: chemistry, technology, and human nutrition. Maryland: Marcel Dekker, 1989. p.245-337.

ZEBROWSKA, T.; DLUGOLECKA, Z.; PAJAK, J.J. et al. Rumen degradability of concentrate protein, amino acids and starch, and their digestibility in the small intestine of cows. Journal of Animal and Feed Science, v.6, n.4, p.451-470, 1997.

ZEOULA, L.M.; BORGES, I.; PRADO, I.N.P. et al. Valor nutritivo da soja crua em grão e do feno de aveia para ruminantes. Revista UNIMAR, v.16, S1, p.149-164, 1994. 